\title{
Influence of polymer additive molecular weight on surface and microstructural characteristics of electrodeposited copper
}

\author{
R MANU* and SOBHA JAYAKRISHNAN \\ Electroplating and Metal Finishing Technology Division, Central Electrochemical Research Institute, \\ Karaikudi 630 006, India
}

MS received 27 July 2010; revised 10 November 2010

\begin{abstract}
Electrodeposition of copper was done with different molecular weight (MW) polyethylene glycol (PEG) as an additive in the plating bath. The adsorbed layer formed of PEG and chloride ion $\left(\mathrm{Cl}^{-}\right)$in the presence of copper ions has a definite role in controlling the deposition mechanism and the coating characteristics. The adsorption behaviour and suppressor nature of PEG with different MW (200-20000) on the physicochemical and the surface morphological features of the copper deposit were characterized. The results reveal that depending on the adsorption capacity of the intermediate complex, the deposit properties show gradation. There is a range of morphology with particular grain structure for different MW PEG addition. Grain size and the roughness decreased with increase in PEG MW. The concentration of $\mathrm{Cl}^{-}$ion in the plating bath is also significant in determining the deposit mechanism of the bath as revealed from the shift in cathodic potential. The adsorbing power of the complex depends not only on PEG MW but also on $\mathrm{Cl}^{-}$ion concentration. XRD analysis of the copper deposit obtained with low MW PEG showed (220) as the major plane and with high MW PEG the prominent orientation was (111) and (200).
\end{abstract}

Keywords. Metal; coatings; additive; poly ethylene glycol; atomic force microscopy; microstructure.

\section{Introduction}

In modern electroplating industry, copper is rapidly being introduced in chip interconnection technology as a replacement for aluminum in ultra large-scale integration for electronic packaging. Current and future scaling requires metallization into vias and trenches having high aspect ratios. The continuous shrinkage in electronic structure plays a greater role for producing devices in the required size. It has been established that through electrodeposition technique adequate thickness, porosity-free structure and good adhesion can be achieved (Czerwinski 1998; Yamakasi et al 1998; Schlesinger and Paunovic 2000). Although various techniques are concomitantly employed, electrodeposition is unique in considering the cost and easy fabrication. Copper is widely used as an interconnect material in electronic packaging industry. Electrodeposition by copper is a natural choice as it could offer negligible line resistance and low electromigration. Copper electroplating has been of much interest for the interconnection of printed circuit boards (PCBs) and in damascene process. Therefore, copper filling by electroplating has been actively studied. There are many reports on copper deposition by various techniques such as electrodepostion, pulse deposition, chemical vapour deposition (CVD) and physical vapour deposition (PVD) for fabricating copper lines. Electrodeposited copper films have

*Author for correspondence (manupanikker@gmail.com) been widely investigated with respect to their morphological characteristics, electrical properties and corrosion resistance (Seah et al 2001; Wan et al 2003).

Copper plating baths used for forming integrated circuit interconnects typically contain two or three component additive mixtures which facilitate the superfilling of via holes and trench lines during damascene plating. Extensive studies over the last two decades has provided researchers with an understanding of the underlying mechanisms. The role of cuprous intermediate in the copper deposition reaction and the binding nature of the complex formed with various additives are also important in determining the deposition process. In general, at least two additives are employed to achieve superfilling: a polyether such as polyethylene glycol (PEG) and organic sulfur compound such as bis (3-sulfopropyl) disulfide (SPS) or 3-mercapto-1-propanesulfonate (MPS) (Cao et al 2001; West and Mayer Reid 2001; Josell et al 2002). The presence of additive can influence the surface morphology, microstructure and physical properties of metal coating (Oniciua and Muresan 1991; Franklin 1994; Lallemand et al 2002; Gomes and da Silva Pereira 2006; Manu and Jayakrishnan 2009). Among the various additives, PEG serves as a suppressor due to its strong inhibition on reaction kinetics, especially when a halide ion, such as chloride ion $\left(\mathrm{Cl}^{-}\right)$is present. PEG is a good suppressor and have a major role in forming the complex monolayer that gets adsorbed to the substrate. The beneficial effects of adding PEG to an electrolytic bath have motivated growing interest in the 
effects of these additives on the morphology and physical properties of the deposits. As PEG occurs in different MW, there can be difference in adsorptive strength of the complex. Although there are reports on the effect of PEG MW on the filling performance, studies are limited to certain MW of PEG only. Also, surface topographical feature and the change in orientation of different planes of the deposit with different MW PEG are not well documented. Depending on MW, there can be difference in projective coverage of the adsorbed layer over the substrate. This could definitely influence the deposition character and the properties such as thickness, conductivity etc of the deposit. In general, the effects of PEG on the morphological characteristics of electrodeposited coatings mainly stem from the adsorption of additive molecules on the electrode surface (Yokoi et al 1983, 1984; Stoychev and Tsvetanov 1996; Trejo et al 2001; Hebert et al 2005; Ya et al 2005; Bozzini et al 2006). However, in spite of numerous studies on the effects of polyethoxylated compounds on coating characteristics, little is known about the mechanism underlying the adsorption of these compounds on the electrode surface.

As chloride is a key additive in the copper plating bath, various concentrations of chloride $\left(\mathrm{Cl}^{-}\right)$ion in the presence of PEG of different MW is used for the present study (Reid and David 1987; Jovi'c and Jovi'c 2001; Feng et al 2003; Kao et al 2005; Dow et al 2008). In this study, electrochemical technique such as cyclic voltammetry and cathodic polarization analysis was employed to know the effect of MW of PEG on modifying the deposition mechanism. X-ray diffraction (XRD), scanning electron microscopy (SEM) and atomic force microscopy (AFM) techniques were used to characterize the microstructure and surface topography of the copper deposits produced from baths containing PEG of different MW. X-ray photoelectron spectroscopy (XPS) was employed to know the concentration of various elements in the copper deposit.

Many reports are available on reaction of PEG in the presence of $\mathrm{Cl}^{-}$forming a complex film that gets adsorbed on the substrate and inhibit subsequent reduction of $\mathrm{Cu}^{2+}$ (Healy and Pletcher 1992; Kelly and West 1998a, b; Gabrielli et al 2004; Bozzini and Sugura 2006). However, studies are limited to a particular type of PEG molecule. The adsorptive behaviour of the complex has a direct influence on the deposit property, as it is known that the nature of the adsorbed layer, the nucleation and the growth depends on the coverage by the adsorbed monolayer. Adding PEG alone to copper bath could have influence in the deposition structure. Depending on the MW of PEG, the adsorbing power of the complex also differs. PEG of high MW has high projective coverage and has more suppressive nature compared to PEG of lower MW. Here the modification in surface morphology of the copper deposit brought about by PEG MW has significance in determining physicochemical and metallurgical properties of the copper deposit.

\section{Experimental}

A thin copper sheet of $0.5 \mathrm{~mm}$ thickness was used as the substrate for the present study. The size of the substrate was $200 \times 100 \times 0.5 \mathrm{~mm}$. The copper substrate was precleaned before electrodeposition. The substrate was degreased with acetone and then cathodically polarized in alkaline cleaner for 2 min under a current strength of $2 \mathrm{~A} / \mathrm{dm}^{2}$, then washed thoroughly with distilled water before plating. The composition of the various components in the plating bath is copper sulphate, sulphuric acid and chloride as $\mathrm{NaCl}$. For the present study, PEG of different MW in the range of 200 20000 was used. The concentrations of various bath components are described in table 1 . All the chemicals were of analytical grade and Millipore-Q water was used for making solutions. The various bath components were individually added to the plating bath through dilution from stock solution prepared with properly concentrated contents of these additives. The temperature of the plating solution was maintained at $30 \pm 2^{\circ} \mathrm{C}$. The current density applied was $3 \mathrm{~A} / \mathrm{dm}^{2}$ and the plating time, $15 \mathrm{~min}$. The roughness of the deposit was tested by surface roughness tester of model SJ-301 of Mitutoyo make having a sensitivity of $0.5 \mu \mathrm{m}$. The cathode efficiency was obtained by measuring the actual weight of the deposit and applying in the standard equation. The thickness of the deposit was determined by the difference in weight before and after deposition. The hardness of the deposit was tested by hardness tester applying a load of $10 \mathrm{gf}$ and was expressed as Vicker's hardness number.

The change in cathodic potential with respect to metal deposition during electrodeposition has been monitored by using a reference electrode. Cyclic voltammetric (CV)

Table 1. Composition of plating bath.

\begin{tabular}{llllllll}
\hline Bath ingredients & Bath A & Bath B & Bath C & Bath D & Bath E & Bath F & Bath G \\
\hline Copper sulphate & $90 \mathrm{~g} / \mathrm{l}$ & $90 \mathrm{~g} / \mathrm{l}$ & $90 \mathrm{~g} / \mathrm{l}$ & $90 \mathrm{~g} / \mathrm{l}$ & $90 \mathrm{~g} / \mathrm{l}$ & $90 \mathrm{~g} / \mathrm{l}$ & $90 \mathrm{~g} / \mathrm{l}$ \\
Sulphuric acid & $120 \mathrm{~g} / \mathrm{l}$ & $120 \mathrm{~g} / \mathrm{l}$ & $120 \mathrm{~g} / \mathrm{l}$ & $120 \mathrm{~g} / \mathrm{l}$ & $120 \mathrm{~g} / \mathrm{l}$ & $120 \mathrm{~g} / \mathrm{l}$ & $120 \mathrm{~g} / 1$ \\
Chloride $\left(\mathrm{Cl}^{-}\right)$ & $30 \mathrm{ppm}$ & $30 \mathrm{ppm}$ & $30 \mathrm{ppm}$ & $30 \mathrm{ppm}$ & $30 \mathrm{ppm}$ & $30 \mathrm{ppm}$ & $30 \mathrm{ppm}$ \\
Polyethylene & $*$ MW 200 & MW 400 & MW 600 & MW 4000 & MW 6000 & MW 8000 & MW 20000 \\
glycol (PEG) & $200 \mathrm{ppm}$ & $200 \mathrm{ppm}$ & $200 \mathrm{ppm}$ & $200 \mathrm{ppm}$ & $200 \mathrm{ppm}$ & $200 \mathrm{ppm}$ & $200 \mathrm{ppm}$ \\
\hline
\end{tabular}

*MW: Molecular weight of PEG. 
analysis of copper deposit with respect to various plating baths were done using Autolab PGSTAT 30. CV analysis was conducted in the potential range from -0.8 to $+0.8 \mathrm{~V}$ to examine the effects of $\mathrm{PEG}$ and $\mathrm{Cl}^{-}$on copper deposition and dissolution at a sweep rate of $50 \mathrm{mV} / \mathrm{s}$. A three-electrode system was used for electrochemical experiments. Where glassy carbon with an exposed surface area of $0.08 \mathrm{~cm}^{2}$ served as the working electrode, a $\mathrm{Cu}$ bar was used as the counter electrode. A saturated calomel electrode (SCE) served as the reference electrode. All the potentials refer to the potentials vs SCE.

The change in crystallographic orientation and the preferential plane of the copper deposit was identified by XRD analysis using a PAN analytical machine PW 3040/60 X'pert PRO. The grain size of the deposit was calculated using full width at half maximum value, applying the Scherrer's formula. The surface morphology of the copper deposit was taken by scanning electron microscope (SEM) of JEOL 2000 model under different magnifications. Atomic force microscope (AFM) studies were also performed to view the threedimensional topography of the deposit and these were compared. The topographic analysis of the electroplated sample was performed using a commercial AFM (molecular imaging, USA, Pico scan 2100) instrument in contact mode. X-ray photoelectron spectroscopy (XPS) of the copper deposit was done using Multilab-2000, Thermoscientific make having $\mathrm{Mg} \mathrm{K} \alpha$ as the source to detect the trace element in the deposited sample. Copper-deposited samples were used as such for analysis without any prior surface treatment. Sample size of $1 \times 1 \mathrm{~cm}$ was cut and mounted on the sample stub using silver paint, dried and inserted in the chamber and kept overnight to get the required vacuum of $10^{-10}$ mbar. Measurements were carried out after the vacuum was reached.

\section{Results and discussion}

\subsection{Physical properties of copper deposit}

The properties of copper deposit obtained with different MW PEG addition are compared in table 2. The hardness of the copper deposit was more or less same with respect to increase in PEG MW, although slight difference in hardness value with respect to PEG-400 was observed. PEG having low MW, viz. 200-600, have random nucleation sites on the adsorbed layer and the weak suppression of the complex leads to uncontrolled growth causing decrease in hardness. Here nucleation results in non-uniform growth of overlayers leading to irregular deposit microstructure. Obviously, internal stress and structural inhomogeneity within the copper deposit will be high and will reduce the hardness. But with high MW PEG, i.e. $>6000$, there is more inhibition from the adsorbed layer over the cathode surface and through ordered and abundant defects in the adsorbed monolayer, metal ions get nucleated and the progressive growth of layers leads to better coating feature. The increase in hardness can be ascribed to the compact and uniform growth showing an even growth in lateral and vertical planes with respect to high MW PEG molecule.

The cathode efficiency was low for low MW PEG as compared to high MW. The decrease in cathode efficiency with respect to low MW PEG can be attributed to hydrogen evolution during deposition. The adsorbed film formed with high MW PEG could act as inhibitors of hydrogen adsorption and the presence of more metal cations increased the ionic mobility that increase the cathode potential improving the cathode efficiency. The thickness of the deposit was almost same with slight difference in the case of copper deposit obtained at high MW PEG.

The roughness is a measure of the uniformity of the metal deposit with respect to plating conditions. The roughness of the deposit was low for copper deposit obtained with high MW PEG. As with high MW PEG, more uniform deposition resulted in smooth deposit morphology. But with low MW PEG the copper deposit was dull and non-uniform, having rougher surface feature. This was clear from AFM studies also. The roughness was $\approx 0.3 \mu \mathrm{m}$ higher for low MW PEG compared to high MW PEG. The difference in inhibition nature of the monolayer complex can influence the growth of metal layers.

\subsection{Electrochemical characterization of copper deposits}

Molecular weight of PEG has significant influence in shifting the overpotential of the cathode electrode as is clear from

Table 2. Physical properties of copper deposit.

\begin{tabular}{|c|c|c|c|c|}
\hline $\begin{array}{l}\text { Plating bath composition } \\
\qquad\left(\mathrm{CuSO}_{4} 5 \mathrm{H}_{2} \mathrm{O}+\mathrm{H}_{2} \mathrm{SO}_{4}+\mathrm{Cl}^{-}\right)+\end{array}$ & $\begin{array}{l}\text { Hardness } \\
(\mathrm{VHN})\end{array}$ & $\begin{array}{l}\text { Thickness } \\
(\mu \mathrm{m})\end{array}$ & $\begin{array}{l}\text { Cathode }(\%) \\
\text { efficiency }\end{array}$ & $\begin{array}{l}\text { Roughness } \\
(\mu \mathrm{m})\end{array}$ \\
\hline PEG 200 & 244 & $6 \cdot 8$ & $81 \cdot 25$ & 0.53 \\
\hline PEG 400 & 270 & $6 \cdot 8$ & $79 \cdot 56$ & 0.57 \\
\hline PEG 600 & 321 & $6 \cdot 9$ & $80 \cdot 30$ & 0.54 \\
\hline PEG 4000 & 352 & $7 \cdot 3$ & $81 \cdot 56$ & 0.35 \\
\hline PEG 6000 & 360 & $7 \cdot 4$ & $84 \cdot 31$ & $0 \cdot 28$ \\
\hline PEG 8000 & 370 & $7 \cdot 4$ & $85 \cdot 15$ & $0 \cdot 23$ \\
\hline PEG 20000 & 365 & $7 \cdot 5$ & $85 \cdot 54$ & $0 \cdot 25$ \\
\hline
\end{tabular}


figure 1 . The adsorptive coverage by the complex layer is the prominent factor determining the nucleation and growth in electrodeposited metal coating. The degree of suppression is influenced by the PEG MW and the addition of high MW PEG has the strongest suppression ability. PEG with high MW has more coverage, thereby polarizing the electrode and shifting the potential to more negative values. This polarizing effect is probably due to the suppression of the cathode surface by the additives, which raises the local cathode current density. This shift in overpotential could affect the growth of metal layers, where the metal nucleation rate depends on the

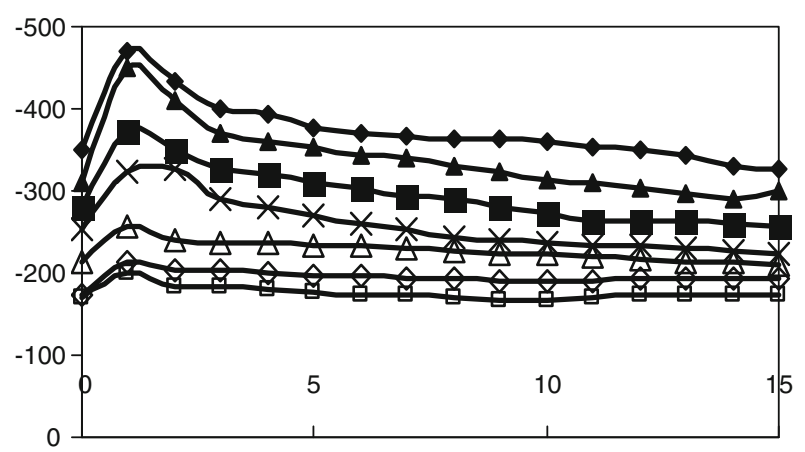

(c)

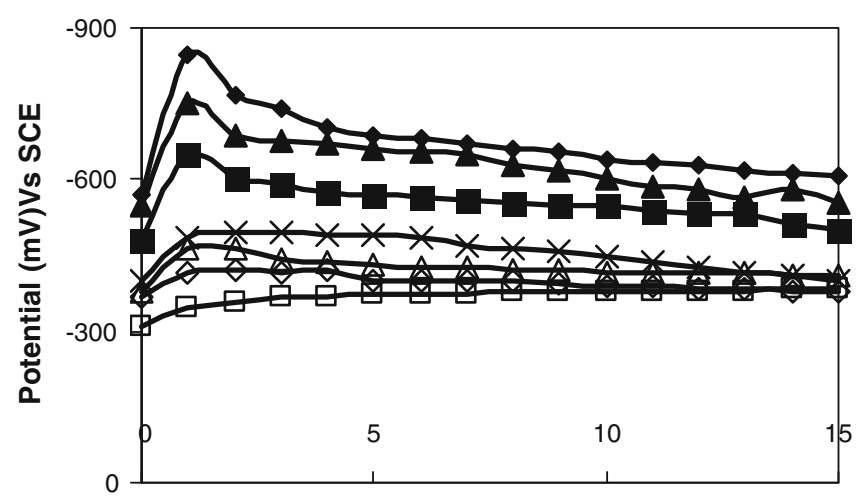

(b)

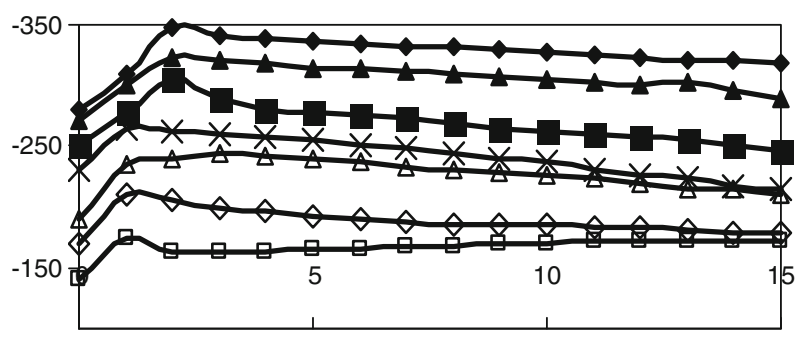

Time, minutes (a)

Figure 1. Change in cathode potential with plating time during galvanostatic copper electroplating using copper plating bath containing PEG of different MW and chloride: (a) $30 \mathrm{ppm}$, (b) $50 \mathrm{ppm}$ and (c) $100 \mathrm{ppm}\left(\square-\right.$ copper + PEG (200) $+\mathrm{Cl}^{-}, \diamond-$ copper + PEG $(400)+\mathrm{Cl}^{-}, \Delta-$ copper + PEG $(600)+\mathrm{Cl}^{-}, \mathrm{x}-$ copper + PEG $(4000)+\mathrm{Cl}^{-}, \boldsymbol{\square}-$ copper + PEG $(6000)+\mathrm{Cl}^{-}, \boldsymbol{\Delta}-$ copper + PEG $(8000)+\mathrm{Cl}^{-},-$copper + PEG $\left.(20,000)+\mathrm{Cl}^{-}\right)$. availability of defect sites over the substrate surface. According to the principles of electrocrystallization, the rate of formation of nuclei on the electrode surface increases exponentially as the cathodic overpotential increases (Brongersma et al 1999). From figure $1 \mathrm{~b}$ it is clear that the cathodic polarization was high for copper deposit with high MW PEG, viz. 6000 and 8000 compared to low MW PEG. The shift in cathodic potential was prominent at the initial stage of deposition. This shift in cathode potential could alter the deposition nature of the copper electrodeposit bringing change in surface morphological and other relevant properties of the deposit. Here the concentration of $\mathrm{Cl}^{-}$ion is also significant in shifting the cathode potential. The influence of different concentrations of $\mathrm{Cl}^{-}$ion on deposition mechanism is illustrated in the subsequent section.

The cyclic voltammograms of the copper deposit obtained with different bath formulations are shown in figure 2. In all cases, there appear two peaks irrespective of the PEG MW, in the forward and reverse scans of the cyclic voltammogram. From the curve it is clear that with respect to different $\mathrm{MW}$, there is change in area during forward and reverse scans. Where high MW PEG has better adsorption nature and which are having more ether groups that facilitate good binding strength between the anchors (chloride ions) and the PEG molecule that gets coordinated to $\mathrm{Cu}$ ions. From the area of the two peaks the surface coverage by different types of PEG molecules and the corresponding shift in cathodic potential can be assigned. It is clear that a complex formed with low MW PEG has inferior suppression on cathode electrode as revealed from the area of the peak. At lower potential the complexes formed with low MW PEG desorbs while complex formed with high MW still remains on the electrode surface. It is clear from cyclic volammetric analysis that with high MW PEG, the peak has shifted to more negative in the reverse scan. The shift in cathodic potential to more negative values shows the more suppressive nature of the complex formed with high MW PEG. In the case of high MW

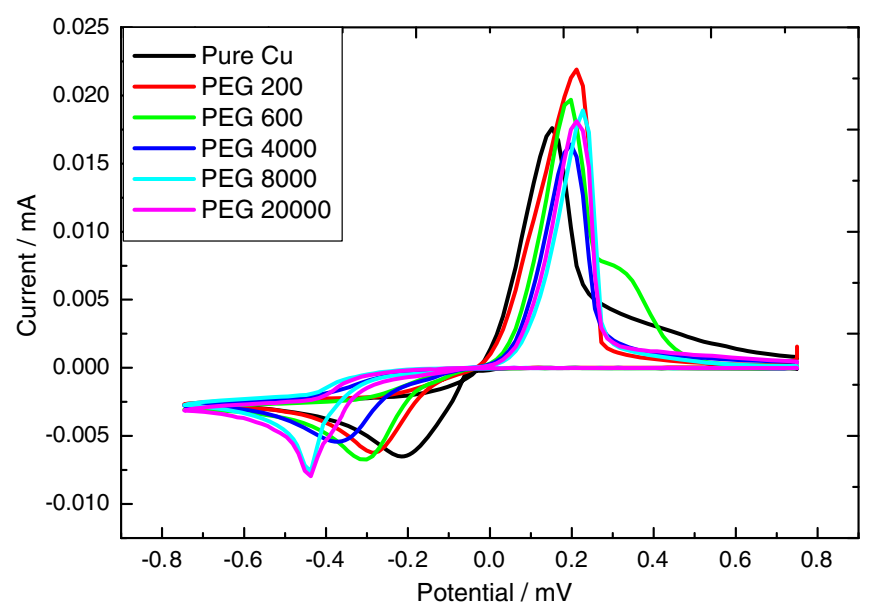

Figure 2. Cyclic voltammetric study of copper deposit from plating bath deposit containing PEG of different MW. 
PEG the maximum of cathodic peak for $\mathrm{Cu}^{2+}$ reduction is shifted towards more negative values with a reduction of its area revealing an inhibition in electrocrystallization. There is hysteresis in all the cases irrespective of additive modification and this corresponds to irreversible change in surface chemistry during progress of deposition. From this it is clear that with respect to PEG MW the adsorption strength of the additive complex varies which determines the nucleation and morphology of the deposit.

\subsection{Effect of $\mathrm{Cl}^{-}$ion in cathode polarization}

There have been numerous studies showing the formation of $\mathrm{Cl}^{-}-\mathrm{Cu}^{+}-\mathrm{PEG}$ complex and its adsorption on the substrate surface when $\mathrm{Cl}^{-}$is added to PEG containing plating bath (Kelly and West 1998a, b; Feng et al 2003). Due to the presence of PEG and $\mathrm{Cl}^{-}$ions in the acidic copper sulphate bath, significant inhibition of copper electrodeposition was noted. It was observed that below a critical overpotential, chloride ions hold a film of PEG onto the electrode surface and that this film is composed of PEG-cuprous chloride complex. It was suggested that adsorption of chloride ions changed the preferred growth plane of the copper deposit. Although concentration of PEG has practically no influence on the shape of the polarization diagrams, while the concentration of chloride ions significantly influence the nature of the polarization curves (figures 1a, b and c). Three different concentrations of chloride, viz. $30 \mathrm{ppm}, 50 \mathrm{ppm}$ and $100 \mathrm{ppm}$ were added to the plating bath having different MW PEG as additive. As reported elsewhere, presence of $\mathrm{Cl}^{-}$ion could influence the copper electrodeposition as is noted from the shift in cathodic overpotential. Chloride concentration is important in determining the strength of the adsorbed layer formed with PEG. It is clear from cathodic potential measurement that there is polarization with respect to $\mathrm{Cl}^{-}$ion containing bath. Cathodic polarization was less for deposition performed at lower concentration of $\mathrm{Cl}^{-}$. The potential shift can be due to $\mathrm{Cl}^{-}$ions, which are good depolarizers for copper electrodeposition. Polarization can be due to formation of salt film/adsorption of complex on the electrode surface. As more amount of $\mathrm{CuCl}$ is precipitated, increase in copper reduction is observed. At lower concentration of chloride (30 ppm) there is more depolarization compared to at high concentration $(50 \mathrm{ppm})$ where polarizing effect was observed. But at higher $\mathrm{Cl}^{-}$ion concentration $(100 \mathrm{ppm})$ the polarizing effect was low. Depending on the concentration of halide ion the cathodic polarization can differ (Kelly and West 1998a, b; Feng et al 2003). This can be ascribed to the precipitation of cuprous chloride when its solubility limit was reached by adding $50 \mathrm{ppm} \mathrm{Cl}^{-}$causing depolarization during progress of deposition. It is clear that lower concentrations of $\mathrm{Cl}^{-}$ ions have depolarizing effect with polarizing effect greater at higher concentrations. From figure $1 b$ it is clear that there is a shift of $\approx 400 \mathrm{mV}$ in cathode potential as the concentration of $\mathrm{Cl}^{-}$ion increased from 30 to $50 \mathrm{ppm}$. Although there

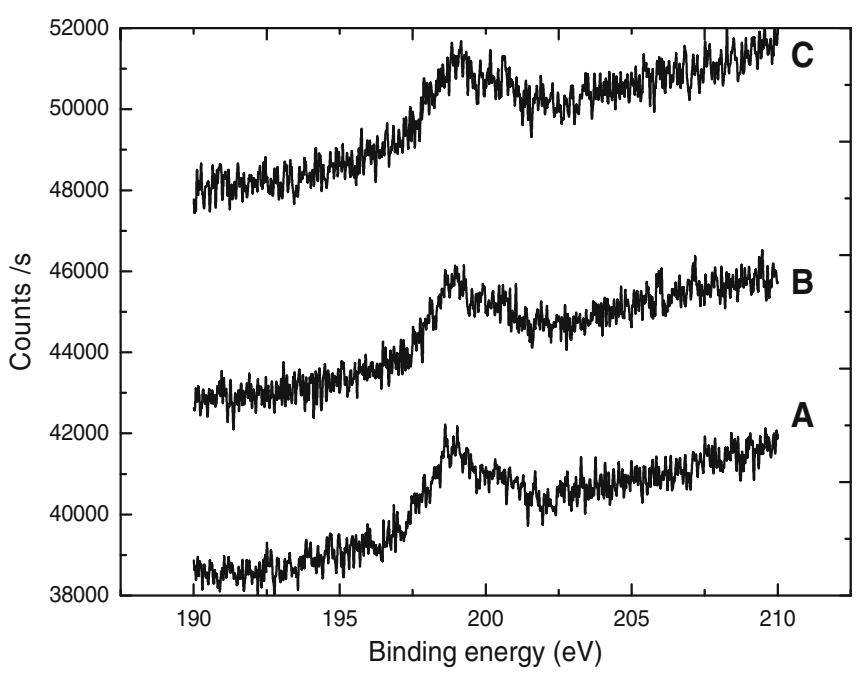

Figure 3. XPS analysis of copper deposit showing concentration of chloride: A. 30 ppm, B. 50 ppm and C. 100 ppm chloride in the plating.

is change in cathode potential with respect to polymer MW, the potential shift is less compared to change caused by presence of $\mathrm{Cl}$. The XPS analysis of the copper deposit showed some gradation in chloride concentration of the deposit (figure 3). This reflects the increased precipitation of chloride as $\mathrm{CuCl}$ during deposition. It was found that the anion could be a complex former and even codeposited with cupric ion during copper electroplating (Carneval et al 1981; Hayase et al 2002). Incorporation of chloride within copper deposit can occur during electrodeposition that may subsequently reduce the chloride content in the plating bath bringing about a change in suppression character of the complex. From this it is clear that by optimizing halide ion concentration in the plating bath good quality deposit with well-refined morphological features can be obtained.

\subsection{XRD analysis}

With the addition of different MW PEG the texture of the deposit changed, indicating that the additives obviously affected the crystallographic orientations of copper deposits (figure 4). For copper deposit the major orientations are (111) (200) (220) and (311). With low MW PEG the copper deposit has (220) orientation and was prominent for PEG having 200, $600 \mathrm{MW}$. The fraction of (111) plane increases considerably as the PEG MW increased. This predominance growth in the direction of (111) plane can be attributed to the higher cathode overpotential which have less surface energy, where the suppression is more due to adsorptive coverage by the large PEG molecule. Consequently the intensity of (220) plane becomes less at high MW PEG addition. The complex formed with high MW PEG has better adsorption nature and this could result in more inhibition. This inhibitive strength 


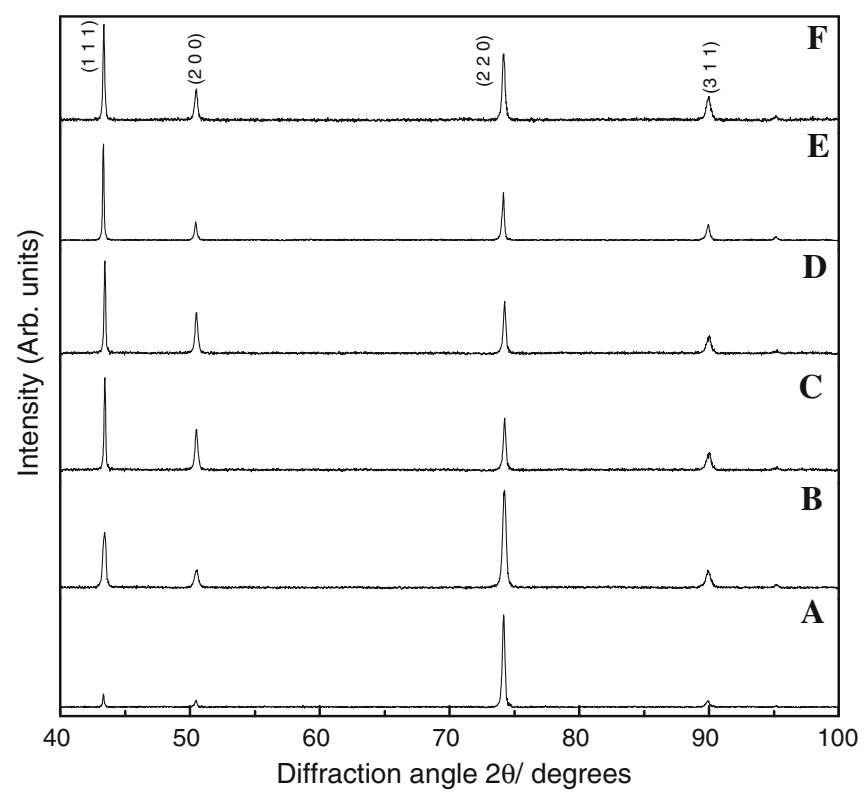

Figure 4. XRD analysis of copper deposit obtained from different plating baths: A. copper + PEG $(200)+\mathrm{Cl}^{-}$, B. copper + PEG $(600)+\mathrm{Cl}^{-}$, C. copper + PEG $(4000)+\mathrm{Cl}^{-}$, D. copper + PEG $(6000)+\mathrm{Cl}^{-}$, E. copper + PEG $(8000)+\mathrm{Cl}^{-}$and $\mathbf{F}$. copper + PEG (20000) $+\mathrm{Cl}^{-}$.

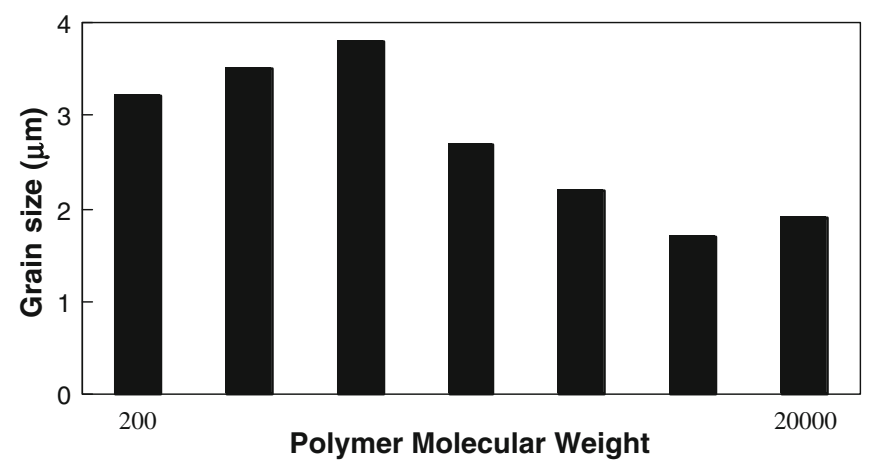

Figure 5. Variation in average grain size of copper deposit with different MW PEG.

may cause a high cathodic potential that could alter the nucleation and growth of the copper deposit. As a result, there can be a change in orientation, whereby the growth of (111) plane, which is of relative lower surface energy than (220) plane can occur. From this we could infer that with respect to different MW PEG addition the texture and the orientation of the various planes shows a marginal difference that could modify the structural properties of the copper electrodeposit. The grain size of the deposit was calculated using Scherrer's formula,

$$
T=\frac{0 \cdot 9 \lambda}{B \cos \theta}
$$

where 0.9 is the Scherrer constant, $\lambda$ the wavelength, $B$ the full width at half maximum value and $\theta$ the angle. The crystallite size of the copper deposit obtained with different MW PEG addition was calculated as per the equation. Figure 5 shows change in average grain size of the copper deposit having different MW PEG. It is clear that the grain size of the deposit shows a gradual increase with respect to PEG MW initially, thereafter the grain size was 1-2 $\mu \mathrm{m}$ less for deposit obtained with PEG-4000 compared to PEG of 200$600 \mathrm{MW}$. It is easy to understand that the increase in grain size is mainly caused by the decrease of cathode overpotential, for the reason that grain growth rather than nucleation predominate over the electrocrystallization process of the copper deposits at lower over potential.

\subsection{Surface morphological characteristics}

The change in surface morphology of the copper deposit with different MW PEG addition is compared in figure 6. There is significant difference in morphology of the copper deposit with respect to PEG MW. The grain size and shape varied from rough crystal structure to uniform and smooth deposit with increase in MW. Although the grain size was small for copper deposit obtained with low MW PEG addition there is non-uniformity in grain size resulting in more coarse structure. There are comparable morphological features for deposit obtained with PEG of MW 400 and 600. But as the PEG MW increases there occurs nodule formation and it is more in the case of PEG-4000. Nodules are composed of copper crystals having crystalline structure and are situated at the periphery of the cathode. Each nodule can be composed of number of grains depending on the deposition condition. For low MW PEG molecule the non-uniform growth and coarse structure increases roughness of the deposit. This was clear from the roughness values. With increase in MW there occurs modification in grain morphology as evidenced from figures 6(C) and (D). The grain morphology was almost similar for PEG of 6000 and $8000 \mathrm{MW}$. The deposit is made of grain conglomerates forming cauliflower-like pattern. It demonstrates that the grain size of $\mathrm{Cu}$ diminishes as the PEG MW increases. Bonou et al (2002) observed that the addition of PEG and $\mathrm{Cl}^{-}$can refine the grain. This is consistent with the conventional concept that a more inhibited surface tends to favour nucleation over crystal growth, resulting in finer grain morphology. PEG with high MW would possess better suppression ability. There is change in grain morphology with the addition of PEG of MW 20,000. From figure 6(G) it is clear that there is slight agglomeration and the roughness was comparable to PEG-8000. As mentioned above, it is difficult for metal ions to diffuse into the metal matrix complex due to geometrical hindrance. Thus, the complex formed with PEG-20,000 tends to distribute more over the upper regions of features than those formed with smaller PEG molecules. There is nodule formation with high MW PEG added deposit and can be ascribed to the change in 

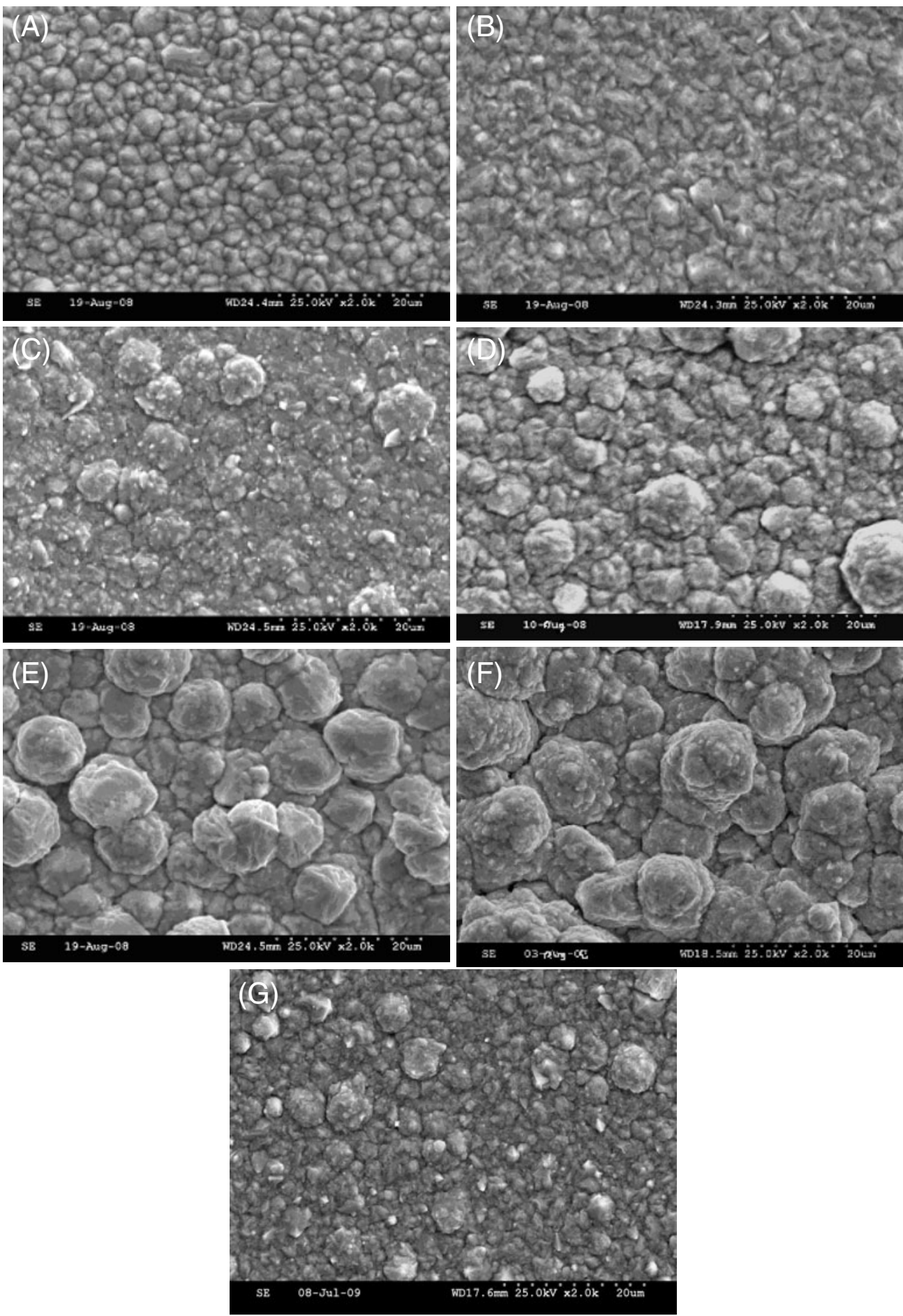

Figure 6. SEM analysis of copper deposit containing PEG of different MW bath compositions: (A) copper + PEG (200) $+\mathrm{Cl}^{-}$, (B) copper + PEG (400) $+\mathrm{Cl}^{-},(\mathbf{C})$ copper + PEG $(600)+\mathrm{Cl}^{-}$, (D) copper + PEG (4000) $+\mathrm{Cl}^{-}$, (E) copper + PEG (6000) $+\mathrm{Cl}^{-}$, (F) copper + PEG (8000) $+\mathrm{Cl}^{-}$ and $(\mathbf{G})$ copper + PEG(20000) $+\mathrm{Cl}^{-}$.

growth rate of various planes resulting in a significant change in microstructure of the deposit. From this it is clear that how slight potential change during initial nucleation can affect the surface morphology of the metal deposit.
The effect of PEG MW on coating characteristics can be summarized as with low MW PEG there is lack of synergistic effect between various additives. This can be due to the fact that with low MW PEG, the adsorbed layer was less 

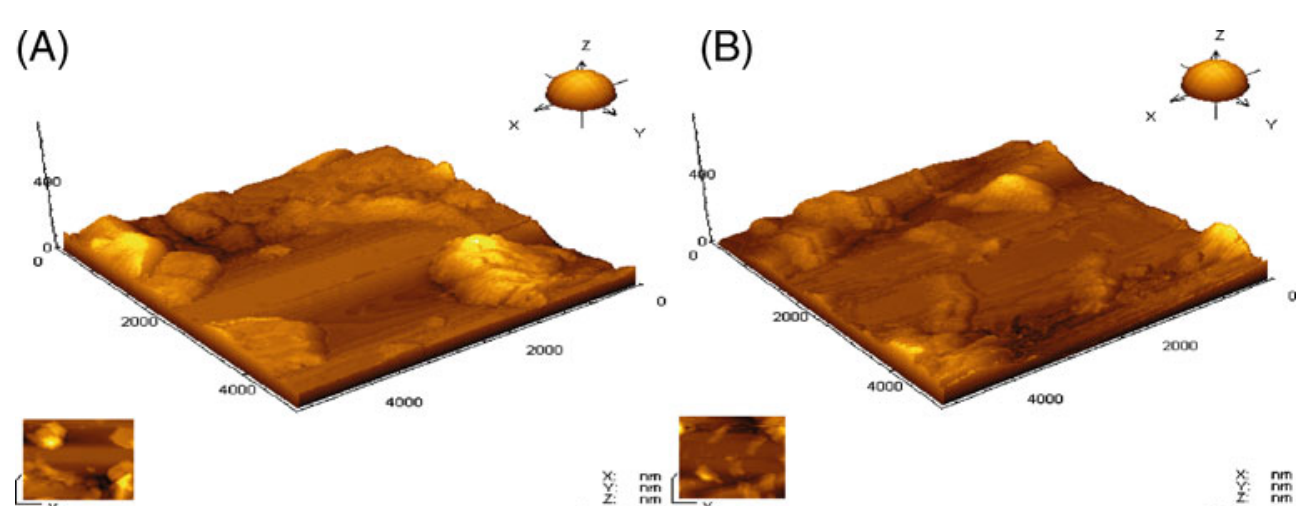

(C)
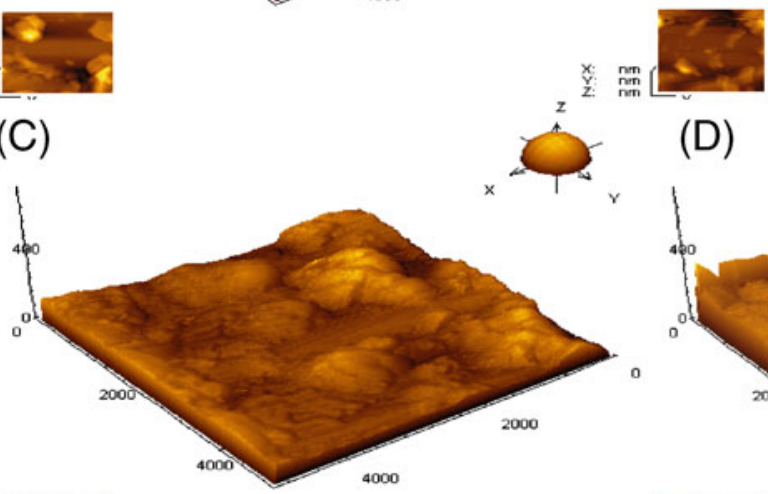

(D)
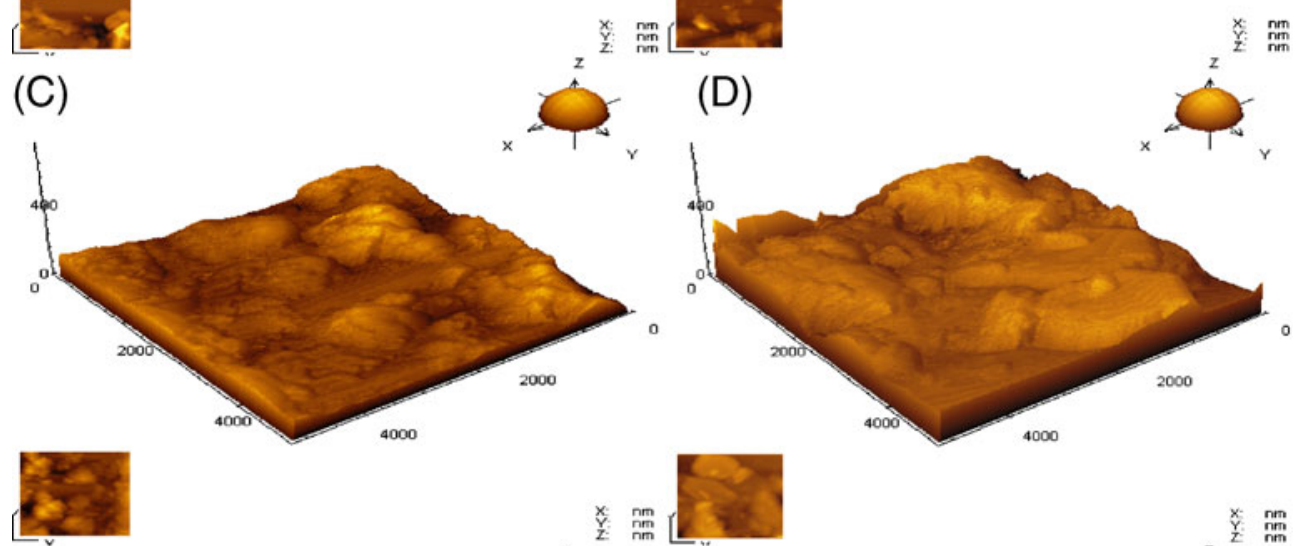

(E)
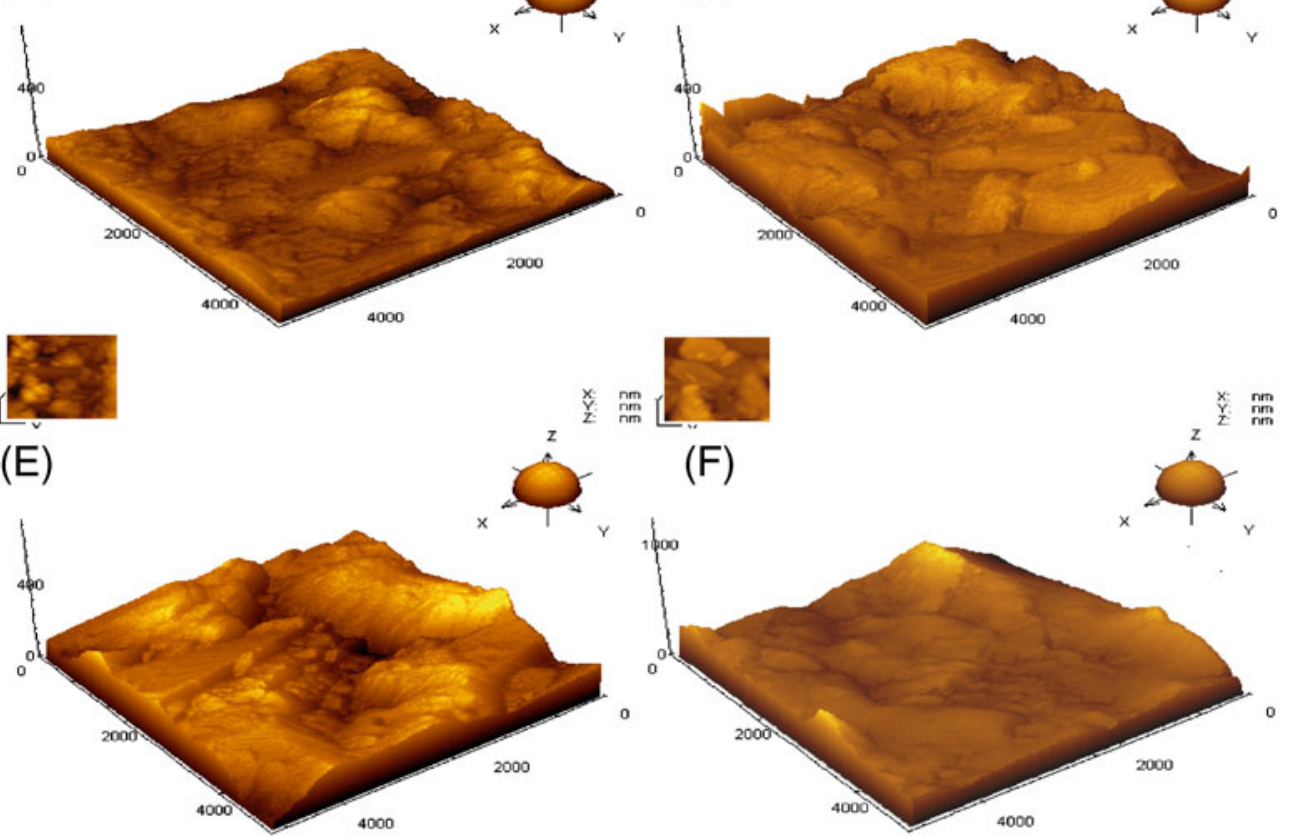

(F)
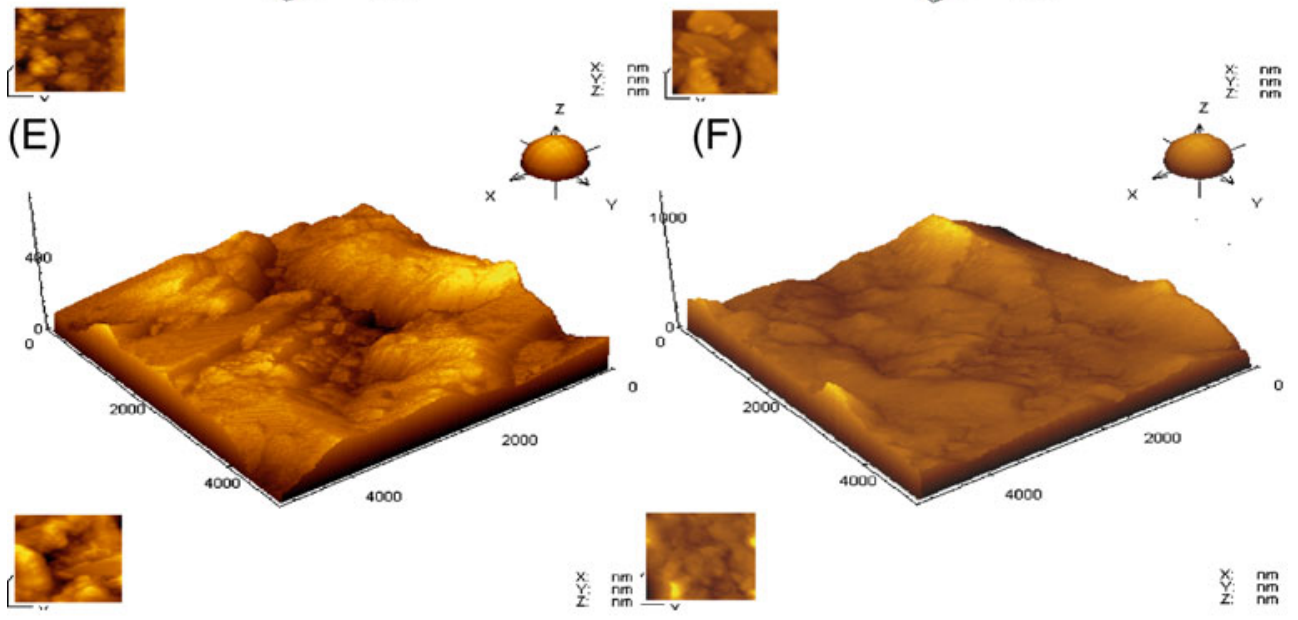

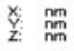

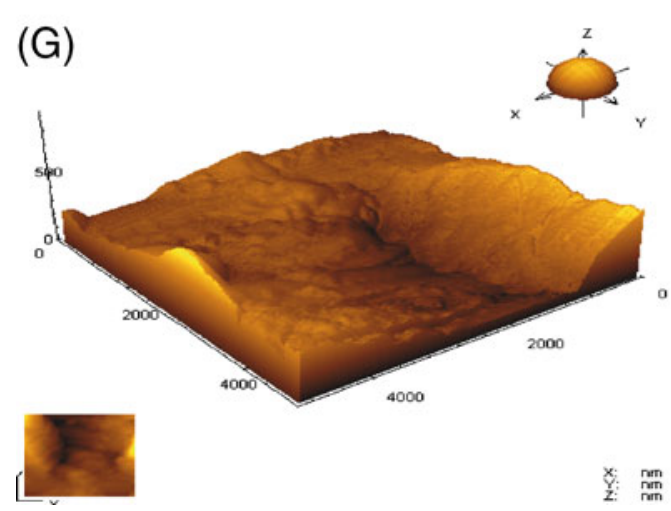

Figure 7. AFM analysis of copper deposit containing PEG of different MW bath compositions: (A) copper + PEG (200) $+\mathrm{Cl}^{-}$, (B) copper + PEG (400) $+\mathrm{Cl}^{-}$, (C) copper + PEG (600) $+\mathrm{Cl}^{-}$, (D) copper + PEG $(4000)+\mathrm{Cl}^{-},(\mathbf{E})$ copper + PEG $(6000)+\mathrm{Cl}^{-},(\mathbf{F})$ copper + PEG $(8000)+\mathrm{Cl}^{-}$ and $(\mathbf{G})$ copper $+\mathrm{PEG}(20000)+\mathrm{Cl}^{-}$. 
suppressive that could not control the arriving copper ions to form uniform growth. This adsorptive behaviour implies that the projective coverage of the $\mathrm{PEG}-\mathrm{Cl}^{-}$complex crucially affects the inhibition of copper deposition, thereby modifying the microstructure of the deposit.

Surface topography of the copper deposit obtained from different MW PEG added bath was compared in figure 7. AFM observation of the copper deposit shows some valleys and peak over the coated surface. The coating was not uniform as is clear from topography of the deposit obtained with low MW PEG. This was the case for copper deposits obtained with lower MW PEG, i.e. 200-600. The growth of the deposit was not uniform and the grains happen to be of non-uniform shape. This is attributed to the fact that with lower MW PEG the adsorption was inferior and the complex formation with $\mathrm{Cl}^{-}$and $\mathrm{Cu}^{2+}$ ions were minimum thereby uniform coverage with additive complex was less likely. But in the case of high MW PEG added bath the deposit structure was smooth and in some areas grain coalescence was observed. The deposit structure was more compact and fine grained with respect to PEG 6000 and 8000. If other plating condition remains steady, the increase in cathodic overpotential would result in a large number of newly formed nuclei. The higher overpotential generally produces a deposit with smaller grain size. This is clear from cathodic potential analysis where there is an increase in overpotential with the PEG MW at the same concentration. Therefore, PEG with high MW exerts a stronger influence over the plating process and thus the parameters for desirable composition are relatively confined. Nevertheless, PEG is needed to stabilize the plating solution that could improve surface morphology with fine-grained structure. This trend suggested the positive influence of PEG as a suppressor additive and its effect on microstructure of the deposit.

\section{Conclusions}

In the present study we examined the adsorption nature of the complex (PEG-Cu-Cl) formed with different MW PEG on properties of electrodeposited copper. It is found that with respect to polymer MW the adsorption capacity of the complex differed as revealed from cyclic voltammetry and cathodic polarization analysis. The adsorptive strength was more for complex formed with high MW PEG. It is clear that low MW PEG has inferior adsorptive strength compared to high MW; with respect to adsorption tendency of various MW PEG and the suppressive nature of the complex, modified the deposit properties. The grain size and morphology of the copper deposit shows notable difference. There occurs nodule formation and the size of the nodule was increased with PEG MW. High MW PEG have better adsorption capacity, which causes polarization of the cathode. The physical properties such as hardness, roughness etc of the deposit also changed significantly. The presence of $\mathrm{Cl}^{-}$ion also has tremendous effect on deposition mechanism. The polari- zation and depolarization nature of the cathode has direct impact on coating structure, which is related to $\mathrm{Cl}^{-}$ion concentration and on the stability of the complex formed with PEG molecule. XRD analysis of the copper deposit obtained with low MW PEG showed (220) as the major plane and with high MW PEG the prominent orientation was (111) and (200).

\section{Acknowledgements}

The authors are grateful to Prof. A K Shukla, Chairman, Solid State and Structural Chemistry Unit, Indian Institute of Science, Bangalore, for identifying the problem and for useful discussion to complete this work. The authors are also thankful to Mr Ravishanker and Mr Ratheesh for taking SEM and AFM analyses of the samples. One of the authors (RM) acknowledges CSIR, New Delhi, for financial support under the research associateship scheme.

\section{References}

Bonou L, Eyraud M, Denoyel R and Massiani Y 2002 Electrochim. Acta 474139

Bozzini B and Sugura I 2006 J. Appl. Electrochem. 36983

Bozzini B, Mele C, D'urzo L, Giovannelli G and Natal S 2006 J. Appl. Electrochem. 36789

Brongersma S H, Richard E, Vervoort I, Bender H, Vandervorst W, Lagrange S, Beyer G and Maex K 1999 J. Appl. Phys. 863642

Cao Y, Taephaisitphongse P, Chalupa R and West A C 2001 J. Electrochem. Soc. 148 C466

Carneval G and Bebczuk de Cusminsky J 1981 J. Electrochem. Soc. 1281215

Czerwinski F 1998 Nanostruct. Mater. 101363

Dow W P, Yen M Y, Liu C W and Huang C C 2008 Electrochim. Acta $\mathbf{5 3} 3610$

Feng Z V, Li X and Gewirth A A 2003 J. Phys. Chem. B107 9415

Franklin T C 1994 Plat. Surf. Finish 8162

Gabrielli C, Mocoteguy P, Perrot H and Wiart R 2004 J. Electroanal. Chem. $\mathbf{5 7 2} 367$

Gomes A and da Silva Pereira M A 2006 Electrochim. Acta 511342

Hayase M, Taketani M, Aizawa K, Hatsuzawa T and Hayabusa K 2002 Electrochem. Solid-State Lett. 5 C98

Healy J P and Pletcher D 1992 J. Electroanal. Chem. 338155

Hebert K R, Adhikari S and Houser J E 2005 J. Electrochem. Soc. $152 \mathrm{C} 324$

Josell D, Wheeler D and Moffat T P 2002 Electrochem. Solid-State Lett. 5 C49

Jovi'c V D and Jovi'c B M 2001 J. Serb. Chem. Soc. 66935

Kao Y L, Li K C, Tu G C and Huang C A 2005 J. Electrochem. Soc. 152605

Kelly J J and West A C 1998a J. Electrochem. Soc. 1453472

Kelly J J and West A C 1998b J. Electrochem. Soc. 1453477

Lallemand F, Ricq L, Bercot P and Pagetti 2002 Electrochim. Acta. 474149

Manu R and Jayakrishnan S 2009 J. Electrochem. Soc. 156 D215

Oniciua L and Muresan L 1991 J. Appl. Electrochem. 21565

Reid J D and David A P 1987 Plat. Surf. Finish 7466 
Safonova T Ya, Khairullin D R, Tsirlina G A, Petrii O A and Vassiliev S Y 2005 Electrochim. Acta $\mathbf{5 0} 4752$

Schlesinger M and Paunovic M 2000 Modern electroplating (New York: Wiley) 4th edn, p. 63

Seah C H, Mrdha S and Chan L H 2001 J. Mater. Process. Technol. 114233

Stoychev D and Tsvetanov C 1996 J. Appl. Electrochem. 26741

Trejo G, Ruiz H, Ortega R and Mea Y 2001 J. Appl. Electrochem. 31685
Wan C, Lei J, Bjelkevog C, Rudenja S, Magtoto N and Kelber J 2003 Thin Solid Films 44572

West A C and Mayer Reid S 2001 J. Electrochem. Solid-State Lett. 4 C50

Yamakasi T, Schlobmacher P, Ehrlich K and Ogino Y 1998 Nanostruct. Mater. 10375

Yokoi M, Konishi S and Hayashi T 1983 Denki Kagaku. 51 460

Yokoi M, Konishi S and Hayashi T 1984 Denki Kagaku. 52218 